\title{
3D Seismic Constraint Definition in Deep-Offshore Turbidite Reservoir
}

\author{
P. Nivlet ${ }^{*}$, F. Lefeuvre ${ }^{2}$, J.L. Piazza ${ }^{3}$ \\ 1 Institut Français du Pétrole, IFP, 1 et 4, avenue de Bois-Préau, 92852 Rueil-Malmaison Cedex - France \\ 2 Total - Exploration \& Production, 26, avenue Larribau, 64018 Pau Cedex - France \\ 3 Total - Exploration \& Production, 2, Place de la Coupole, 92078 Paris-La Défense Cedex - France \\ email: frederick.lefeuvre@total.com - jean-luc.piazza@total.com
}

\begin{abstract}
Résumé - Définition de la contrainte sismique sur un réservoir turbidique en offshore profond Girassol est un champ turbiditique situé dans l'offshore profond Angolais. Les réservoirs de ce champ sont constitués de multiples complexes chenaux-levées s'érodant partiellement. De ce fait, la description de la géométrie des réservoirs, mais également la prédiction quantitative de leurs propriétés physiques s'annoncent a priori comme des problème très complexes. Nous montrons ici qu'il est néanmoins possible d'extraire une information géologique 3D quantitative de haute résolution, en intégrant correctement les différents types de données disponibles (sismique pre-stack 3D haute résolution, données de puits, vitesses sismiques, informations structurale et stratigraphique). Pour cela, nous proposons un workflow qui se divise en trois parties :

- inversion stratigraphique des données pre-stack, afin d'estimer des volumes d'impédances acoustiques et de cisaillement qui expliquent au mieux les données sismiques observées ;

- analyse probabiliste en faciès sismiques des résultats de l'inversion s'appuyant sur une technique d'analyse discriminante ;

- estimation de volumes de proportions de faciès geologiques s'appuyant sur le résultat de l'analyse précédente, où l'on prend en compte les différences de résolution entre faciès sismiques et géologiques afin d'extraire une information géologique moyenne pertinente pour inférer les hétérogénéités des réservoirs à petite échelle.

Finalement, nous obtenons un ensemble de volumes renseignés en proportions de faciès géologiques, utilisés dans une étape ultérieure comme une contrainte spatiale pour la modélisation géologique.
\end{abstract}

\footnotetext{
Abstract - 3D Seismic Constraint Definition in Deep-Offshore Turbidite Reservoir - Girassol is a turbidite field located in deep offshore Angola. This field is particularly challenging in terms of reservoir characterization due to the high complexity of reservoir geology (channel-levees complexes eroding themselves partially). However, by integrating properly the high resolution $3 D$ pre-stack seismic with well data, seismic velocities, stratigraphy and structural information, extraction of a quantitative $3 D$ high resolution geological information becomes possible. The proposed workflow is divided into three parts:

- pre-stack stratigraphic inversion, to estimate 3D acoustic and shear impedance model explaining optimally available seismic data:
}

* Present address: pniv@statoil.com 


\begin{abstract}
- probabilistic seismic facies analysis from the inversion results based on a discriminant analysis technique;
- geological facies proportions computation from the previous step results by a novel approach developed to account for scale differences between seismic facies and detailed geological facies, in order to extract information at the geological scale, and infer the small heterogeneities.

As a result, we obtain a set of $3 D$ geological facies average proportion volumes, which can be used in a further step to better constrain geological modelling.
\end{abstract}

\section{INTRODUCTION}

The petroleum industry has been focusing for more than a decade on giant deep offshore turbidite reservoirs (e.g. Navarre et al., 2002). Because of the high costs of field development and production, it has become necessary to monitor very accurately the dynamic evolution of the field even at early production stages. Developments in 4D acquisition and processing were prerequisites for this challenge (Lefeuvre et al., 2003). The next challenge is to integrate correctly 4D seismic data in history matching, which is currently a very active area of research (e.g. Mezghani et al., 2004).

A successful integration of 4D seismic data requires first a very accurate characterization of the highly heterogeneous reservoirs prior to the start of the production. This reservoir characterization phase is followed by a fine scale geological facies modeling phase (Doligez et al., 2003). The aim of the present paper is to describe how relevant information can be extracted from 3D pre-stack seismic data in order to better constrain the geological modeling process. This constraint will be described as 3D volumes of average proportions of geological facies on the seismic grid. However, the interpretation of seismic amplitudes in terms of geological facies is neither direct, nor unique. Consequently, definition of the seismic constraint requires the integration of seismic data with other sources of data (well logs and cores, structural and stratigraphic interpretations). Because of the differences in scale and resolution between the different types of data to be integrated, and also because of the inherent uncertainties associated with these data, particular attention must be paid to calibration issues.

The workflow we propose for building the 3D seismic constraint consists of three main steps:

- joint pre-stack stratigraphic inversion of seismic data (Tonellot et al., 2001): this step allows estimation of Pand S-impedance models, which optimally explain seismic data while remaining consistent, at the seismic scale, with well log data;

- probabilistic seismic facies analysis, which produces 3D seismic facies probability volumes from the inversion results;

- geological calibration of seismic facies, which combines seismic facies probabilities with geological facies proportions by seismic facies observed at well positions to build the 3D seismic constraint as average proportions of geological facies models.
In this paper, we will first describe the methodology and then discuss its application to the 1999 3D Girassol seismic data.

\section{METHODOLOGY}

\subsection{Joint Pre-Stack Inversion of Seismic Data}

\subsubsection{Stratigraphic Inversion}

During the inversion, geological knowledge, pre-stack seismic amplitudes and well-log data are combined to estimate optimal elastic parameter distributions (P- and S-impedances, density, referred to as $I_{p}, I_{s}$ and $\rho$ in the following), which are consistent with all input data at the seismic scale. In the present study, a joint inversion methodology (Tonellot et al., 2001), has been used to invert simultaneously all the anglestacks. More precisely, the methodology is based on a bayesian formalism (Tarantola, 1987), in which uncertainties on seismic amplitudes and on the elastic model uncertainties are assumed to be described by gaussian probabilities with zero mean, and covariance operators $C_{d}$, and $C_{m}$ associated respectively with data and model uncertainties.

Under these assumptions, the optimal elastic model, in the maximum likelihood sense, minimizes the following objective function:

$$
J(m)=J_{S}+J_{m}=\sum_{[\theta]}\left\|R_{[\theta]}(m) * W_{[\theta]}-d_{[\theta]}^{\text {obs }}\right\|_{C_{d}}^{2}+\left\|m-m^{\text {prior }}\right\|_{C_{m}}^{2}
$$

with:

$m \quad$ elastic parameter model $\left(I_{p}, I_{s}, r\right)$;

$m^{\text {prior }}$ elastic parameter a priori model $\left(I_{p}^{\text {prior }}, I_{s}^{\text {prior }}, \theta^{\text {prior }}\right)$;

$d_{[\theta]}^{o b s}$ seismic amplitudes from the $[\theta]$ angle sub-stack;

$R_{[\theta]}(m)$ reflection coefficient series modeled by applying the Zoeppritz equations, or one of their linear approximations such presented in Aki and Richards (2002), on model $\mathrm{m}$ for the $[\theta]$ angle range;

$\mathrm{W}_{[\theta]}$ angle-dependent wavelet.

Equation 1 can be divided into two parts: a seismic term $J_{s}$ and a geological term $J_{m}$. The seismic term $J_{s}$ measures the misfit between model-predicted and actual angle-stack amplitudes. If the seismic noise is assumed to be uncorrelated from one trace to another, and from one incidence angle interval $[\theta]$ to another, then, the matrix $C_{d}$ is diagonal, with 
variance $\sigma^{2}([\theta])$. This ratio influences the confidence given in each limited angle-stack seismic data. If the ratio is low, high confidence is given to the seismic data. If the ratio is high, seismic information will only be partially incorporated into the optimal impedance distribution, and the optimal model will remain closer to the a priori model.

The geological term $J_{m}$ measures the misfits between $a$ priori and predicted elastic models according to the norm associated to the inverse of the model covariance matrix $C_{m}$. This covariance matrix contains non-null off-diagonal terms, summarized with an exponential covariance operator $\mathrm{c}_{\mathrm{m}}$, which allows adjustment of the confidence in the elastic $a$ priori model values, and in its geometry (Equation 2).

$$
c_{m}\left(x-x_{0}\right)=\Sigma_{m} e-\frac{x-x_{0}}{\lambda}
$$

with:

$\lambda$ correlation length (range) for the uncertainties on $m-m_{\text {prior }}$;

$x, x_{0}$ any position in the seismic grid;

$\Sigma_{m} 3 \times 3$ covariance matrix of uncertainties on differences between $m$ and $m^{\text {prior }}$.

Each term of $\Sigma_{m}$ corresponds to one elastic parameter among $I_{p}, I_{s}, \rho$. Therefore, $\Sigma_{m}$ controls the confidence in the $a$ priori model: with low diagonal terms the optimal model will be very similar to the a priori model, while the difference will increase with higher diagonal terms. The range $\lambda$ controls the confidence on the geometry of the a priori model: low values tend to make the optimal model less continuous than the a priori model.

\subsubsection{Well-to-Seismic Calibration}

In well-to-seismic angle-stack calibration, one wavelet is extracted for each angle-stack. The differences between these signals compensate for some of the pre-processing issues, such as NMO stretch or tuning. In addition, the procedure allows an optimal relocation of wells (in line, CDP and time origin) on the seismic grid. Pre-stack calibration consists of four steps:

- multi-coherency analysis (Dash and Obaidullah, 1970), extracting a zero-phase wavelet for each seismic anglestack, and estimating associated frequency bandwidth, and signal-to-noise ratios;

- multi-well linear phase analysis (Lucet et al., 2000) performed separately on each angle sub-stack, where the initial 0 -phase wavelets are transformed to linear phase wavelets, determined by their time origin, phase shift and normalization coefficient; these 3 parameters are designed so that the synthetics computed from well data on the basis of Aki-Richards equation optimally match seismic data; wells are allowed to move horizontally and vertically in the vicinity of their initial position during the procedure to improve the calibration;
- optimal multi-angle position for each well: given the linear phase wavelets extracted previously, the optimal multi-angle position is the position where the correlation between synthetic and seismic traces for all the considered angle ranges is maximal;

- variable phase and analysis refinement, to improve wellto-seismic calibration at optimal well positions, by deforming the linear phase with a least square minimization of the misfits between synthetic and observed traces.

During this phase, only the wells, which are not too deviated and which have a sufficiently long logged interval, are taken into account. Shorter logged wells can still be repositioned, once the wavelets have been extracted.

\subsubsection{A Priori Model Construction}

The standard procedure to build an a priori model consists of interpolating well log data along a geometrical framework described by structural and stratigraphic constraints. Interpreted horizons and faults on seismic data delineate geological units. For each grid cell of the investigated 3D volume, a correlation surface is drawn parallel to an horizon, or concordant, depending on the sedimentary deposit mode in the unit, and impedance values found at intersections between this surface and the different well paths, if any, are used as a constraint for 2D interpolation (by inverse distance or kriging algorithms). Otherwise, the a priori model is populated with default values. Finally, a low-pass filter is applied to the interpolated model.

The resulting a priori model is constrained at well positions by well $\log$ values. In the inter-well space, the uncertainty on the a priori model and particularly on its low-frequency components is important. Because stratigraphic inversion is not able to update low-frequency information, the resulting optimum model will lack of reliability. Introduction of low-resolution and a low-frequency constraint, derived for instance from NMO or migration velocities, in the a priori modeling phase can attenuate these drawbacks, and improve the reliability of the inversion results. Constraining the a priori model by velocities from velocity analyses is made in three steps (Nivlet, 2004):

- a pre-processing step, where NMO or migration velocities are transformed into smooth low-resolution low-frequency interval velocities $V_{p L F}$ on the $3 \mathrm{D}$ seismic grid, using for instance the Dix equations in combination with some spatial filtering algorithm (such as moving average or factorial kriging);

- a calibration step, where the low-frequency 3D velocities $V_{p L F}$ are calibrated successively to the low-frequency component of $I_{p}, I_{s}$ and $\rho$ well-logs, using a Gardner-like relationship, to build a low-frequency elastic parameter model; this calibration process is illustrated for low-frequency $I_{p}\left(I_{p L F}\right)$ by Equation 3, where the coefficients $a$ and $b$ are estimated using least-square regression between 
$I_{p L F}$ computed from well-logs and $V_{p L F}$ extracted from velocity model at well positions:

$$
I_{p L F}=a V_{p L F} b
$$

- finally, an estimation step, where the calibrated low-frequency 3D model is used as an external drift in the interpolation of well log data along the pre-defined correlation surfaces.

\subsection{Seismic Facies Analysis}

Once optimal impedance models have been estimated from stratigraphic inversion, the next step consists in interpreting them in terms of seismic facies. In this section, we intend to give some theoretical elements about seismic facies analysis. Practical implementation of the methodology to Girassol will be discussed further in the application part of the paper.

\subsubsection{Theoretical Aspects of Facies Analysis}

Facies analysis is based on pattern recognition algorithms. It aims at translating seismic objects, which are described by a set of indirect information, or seismic attributes (such as amplitudes and impedances) into categorical information, which refer to a given reservoir property (such as lithology, fluid content and reservoir quality). In reservoir characterization, there are at least three domains, where facies analysis plays an important role:

- in electrofacies analysis (Hohn et al., 1997), the attributes are well log data, and the result of the analysis is an electrofacies column describing sequence organization and geological heterogeneities along well paths;

- in 2D seismic facies analysis (Fournier and Derain, 1995), the attributes characterize the shape of seismic traces at reservoir level; the analysis results in a 2D seismic facies map, which characterizes the lateral seismic heterogeneity of the reservoir;

- in 3D facies analysis (Nivlet et al., 2004), the attributes characterize the seismic information in a 3D neighborhood around each cell of the seismic grid, and the analysis results in a 3D seismic facies volume.

Direct reservoir information, such as lithological and sedimentological description from cores, may be available at wells. If such information is taken into account as an input to the pattern recognition process, the method is called supervised facies analysis. Mathematically speaking, supervised seismic facies analysis consists in representing each seismic object as a point in a multivariate "attribute" space. Pattern recognition aims then at making a partition of the multivariate space, based on the available training information, testing the relevance of this partition, and finally, using the calibrated partition to assign a seismic facies to any seismic object.

However, in many cases, the well information may not be sufficiently detailed and some geological features may have been missed by the cored wells. In such cases, an unsupervised facies analysis, where the calibration step is preceded by the construction of the calibration database using for instance hierarchical classification procedure, enables the identification of uncored facies.

The difference between these 2 types of analyses is that in the supervised case, the training database includes directly geological information in the interpretation, available at well positions. In the unsupervised case, the facies correspond to clusters of points, which are detected from all the available data, and then need to be a posteriori interpreted in geological terms. Despite these differences, once the training database has been built up in unsupervised analysis, the algorithms are exactly identical and consist of two steps:

- a calibration step: a relationship is calibrated between the considered set of seismic attributes and seismic facies; this calibration step requires a training database where both types of information are available; the calibrated relationship is called a classification function, and its quality is checked for instance by comparing facies predicted by calibrated classification function with initial facies on the training database (direct reassignment test);

- a prediction step: if the quality of the classification function is satisfactory, it is used to predict facies elsewhere.

We will now describe discriminant analysis, which addresses both steps.

\subsubsection{Discriminant Analysis}

Discriminant analysis is known to be a powerful technique for pattern recognition (Hand, 1981). First, since it works in a probabilistic framework, probabilities of good assignment can be associated with the predicted facies. These probabilities are valuable for assessing the reliability of the interpretation. Second, discriminant analysis provides a guide for feature selection. This is useful since many measurements are available, and numerous attributes can be extracted from them. Criteria based on the performance of the discriminant function help in selecting the most relevant features with respect to the prediction problem that should be addressed. Finally, discriminant analysis, through non-parametric algorithms, allows a proper identification of patterns, even if they are non-linear, which is common in geo-sciences.

In practice, let us call $x^{t}=\left(x_{1}, \ldots, x_{p}\right)$ a generic seismic object described by its $p$ seismic attributes and $\left\{C_{1}, \ldots, C_{N}\right\}$ the $N$ seismic facies to which objects have to be assigned. Discriminant analysis computes for each object $\mathrm{x}$ a set of $N$ assignment probabilities $p\left(C_{i} / x\right)$. If the goal of the study is to produce a deterministic interpretation of the object $x$, one may choose to assign $\mathrm{x}$ to the seismic facies with maximal assignment probability. The probability associated 
with such a seismic facies will then be an index of confidence on the assignment: the highest this probability is, the more confident we are on the assignment.

$$
p\left(C_{i} / x\right)=\frac{p\left(x / C_{i}\right) p\left(C_{i}\right)}{\sum_{j=1}^{N} p\left(x / C_{j}\right) p\left(C_{j}\right)}
$$

These assignment probabilities $p\left(C_{i} / x\right)$ are computed using Bayes' rule (Equation 4), which relates them to two kinds of quantities:

- the prior probabilities $p\left(C_{i}\right)$, which express the a priori knowledge on seismic facies proportions; these probabilities may be taken as equal if no a priori information is available;

- the conditional density functions $p\left(x / C_{i}\right)$, which are computed from the available training data; depending on the size of the training population one may use parametric estimates of these probability density functions (making for instance the assumption of gaussian classes), or nonparametric estimates, based for instance on kernel algorithms (Silverman, 1986), if enough training data is available to make reliable statistical estimates.

\subsection{Geological Calibration of Seismic Facies}

Seismic facies analysis results in a set of seismic facies probability volumes. However, seismic facies are not geological facies. Nor are seismic facies probabilities related to proportions of geological facies. We have then to estimate distributions of geological facies $G F_{j}$ proportions for each seismic facies $S F_{i} p\left(\operatorname{prop}_{[}\left[G F_{j} / F S_{i}\right]\right)$ from well log data. Then, by using the total probability axiom, it is possible to combine these distributions with seismic facies probabilities $\mathrm{p}\left(\mathrm{SF}_{\mathrm{i}}\right)$ computed in the seismic facies analysis step in order to estimate distributions of geological facies proportions for each cell of the seismic grid $p\left(\operatorname{prop}\left(G F_{j}\right)\right)$, using a similar approach to that presented in Barens and Biver (2004).

$$
p\left(\operatorname{prop}\left(G F_{j}\right)\right)=\sum_{i=1}^{N} p\left(\operatorname{prop}\left(G F_{j} / S F_{i}\right)\right) p\left(S F_{i}\right)
$$

From these distributions, average proportions of geological facies may be computed, which are to be used as a nonstationary constraint in a further geological and geostatistical modeling step, described in Lerat et al. (2006).

\section{APPLICATION TO THE GIRASSOL FIELD}

\subsection{Data Presentation}

Seismic data consists in 2 time-migrated angle-stacks ([ $3^{\circ}$ $\left.22^{\circ}\right]$ for the near angle-stack and $\left[23^{\circ}-37^{\circ}\right]$ for the far anglestack) recorded in 1999, before the start of production, over the Oligocene turbidite Girassol field (deep-offshore Angola). Each angle-stack has 1071 lines and 2221 crosslines, with a $6.25 \times 6.25 \mathrm{~m}$ seismic bin and a $2 \mathrm{~ms}$ sampling, and covers about $100 \mathrm{~km}^{2}$. Figures $1 \mathrm{~A}$ and $1 \mathrm{~B}$ show near and far angle-stacks. These data are high-resolution, with an average frequency bandwidth at $-6 \mathrm{~dB}$ lying between 21 and $91 \mathrm{~Hz}$ for the near angle-stack and between 16 and $76 \mathrm{~Hz}$ for the far angle-stack. Note that in comparison with conventional seismic data, the seismic bandwidth is shifted toward high frequencies, but with a loss of low frequencies. Seismic data are also characterized by a very high average signal-to-noise ratio (around $18 \mathrm{~dB}$ ), which reveals highquality data. Unfortunately, due to lateral variations of seismic attenuation in the overburden, the seismic dataset also exhibits a strong lateral variation of energy, which needs to be compensated for during the inversion. Figures $2 a$ and $2 b$ a)

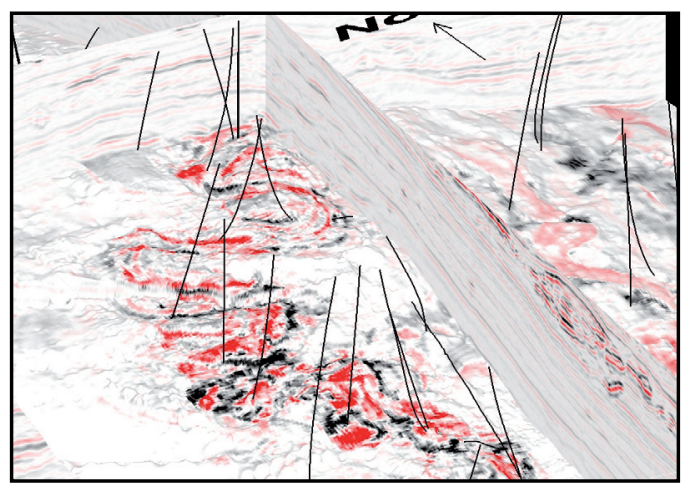

b)

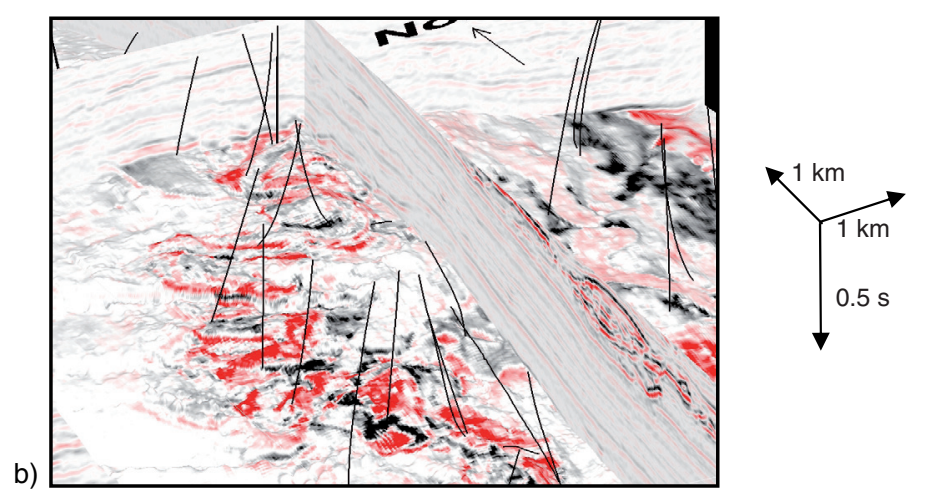

Figure 1

Near (a) and Far (b) angle-stacks. 
a)

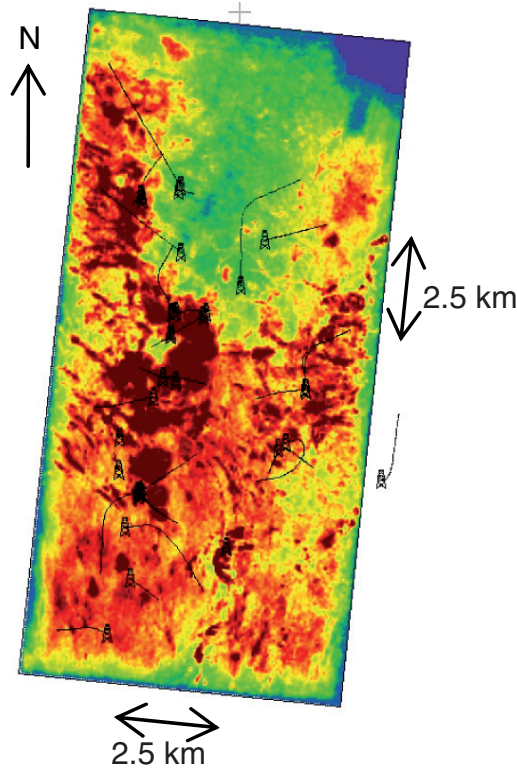

RMS amplitude

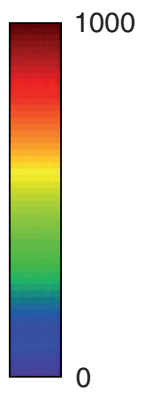

b)

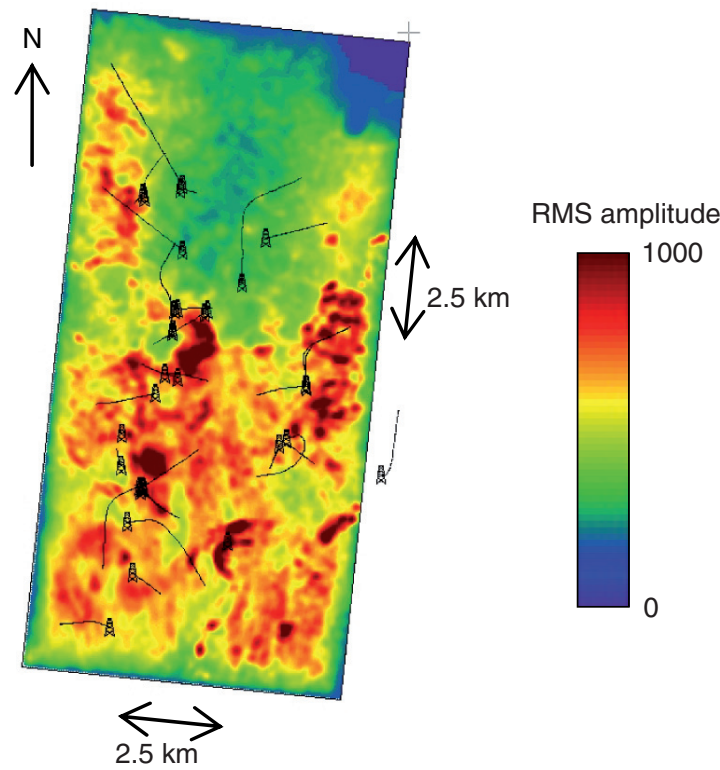

Figure 2

RMS amplitude maps computed over the Oligocene reservoirs from Near (a) and Far (b) angle-stacks.

a)
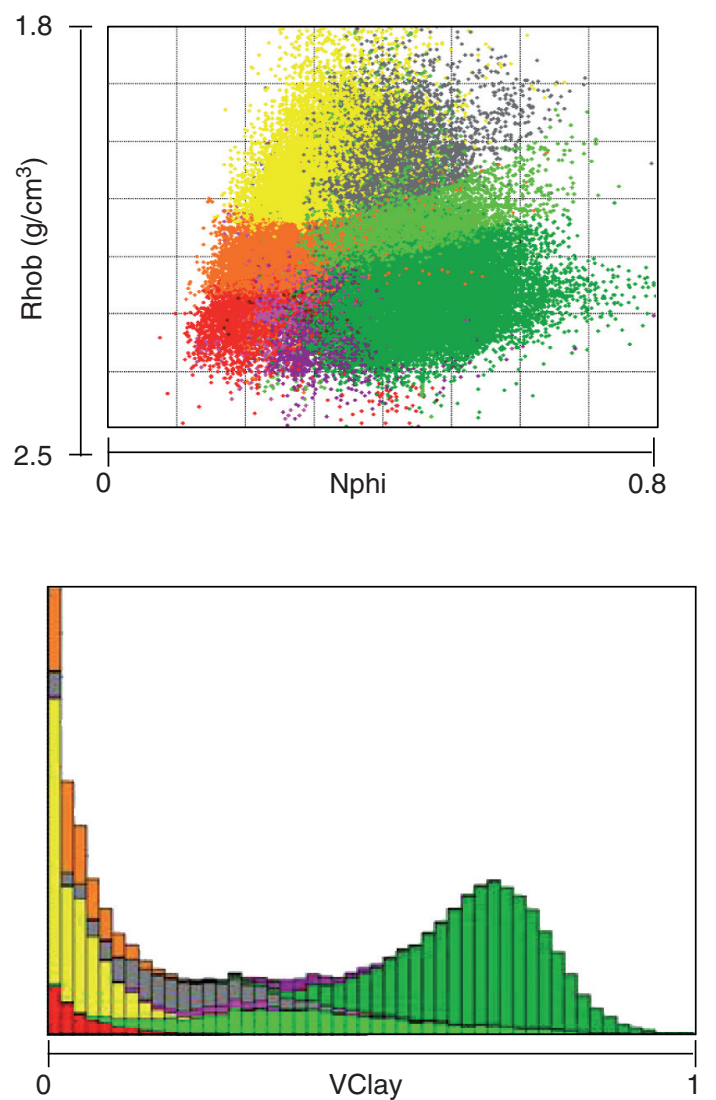

b)

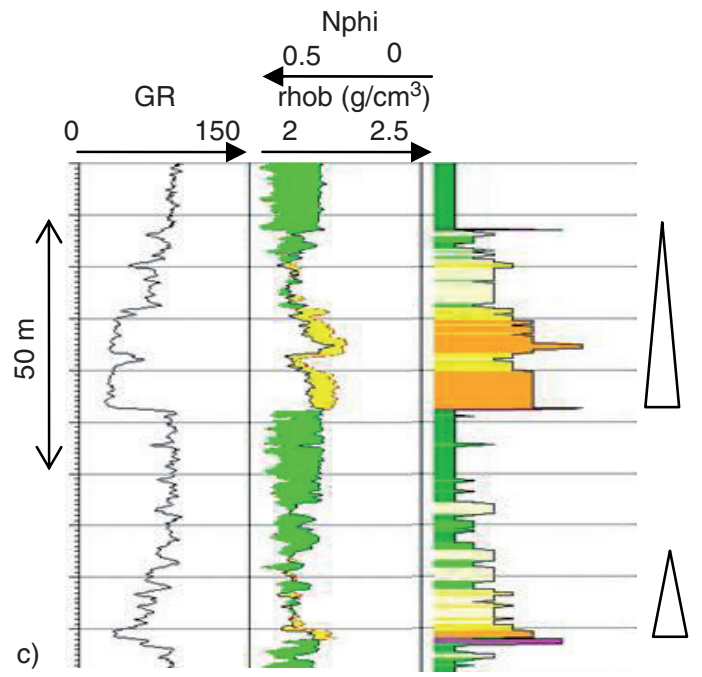

FG2 Massive shales FG4 Laminated shales

FG6 Laminated sandstones

FG8 Massive sandstones

FG10 Coarse sandstones

FG13 Muddy debris-flows

FG14 Sandy debris-flows

FG15 Breccia-lags

Figure 3

Well-log data: Nphi-rhob crossplot (a) and B- VClay histogram (b) from the 40 wells and example of (partial) composite log display (c). 

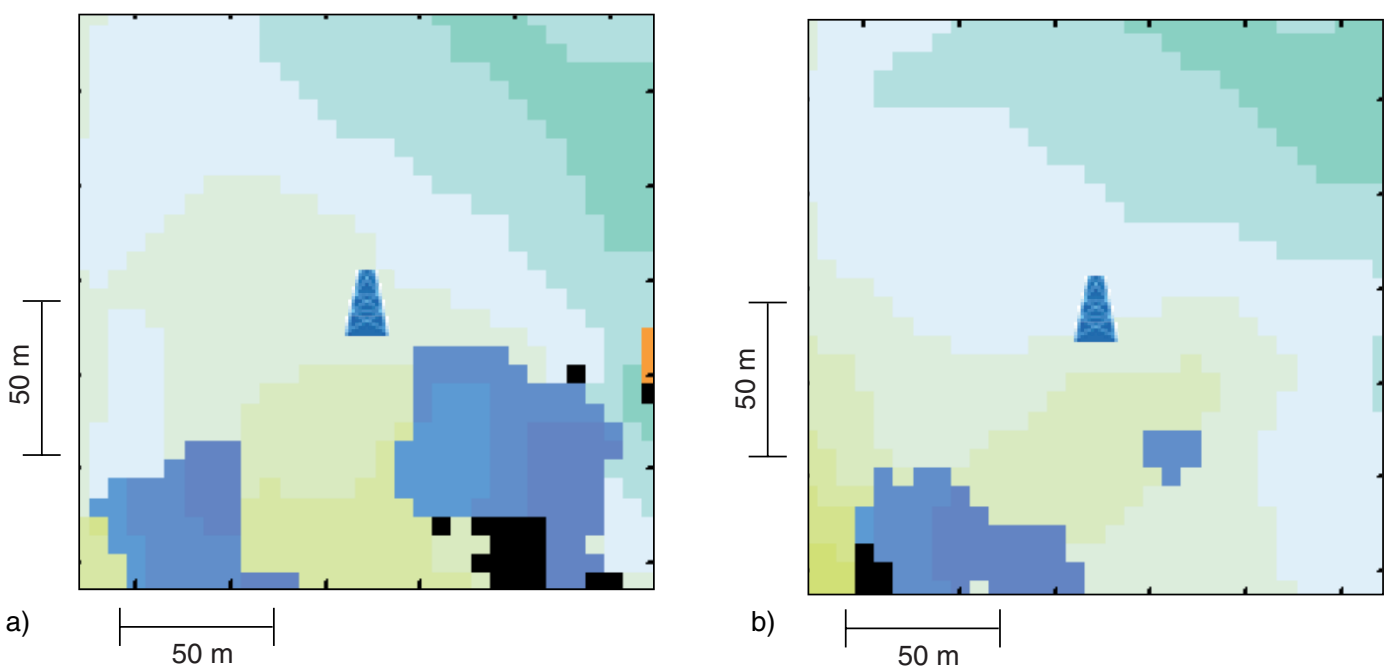

Figure 4

Example of optimal time-shift mini-maps, obtained for optimal well-to-seismic calibration, in the vicinity of one well, and computed from Near (a) and Far (b) angle-stacks.

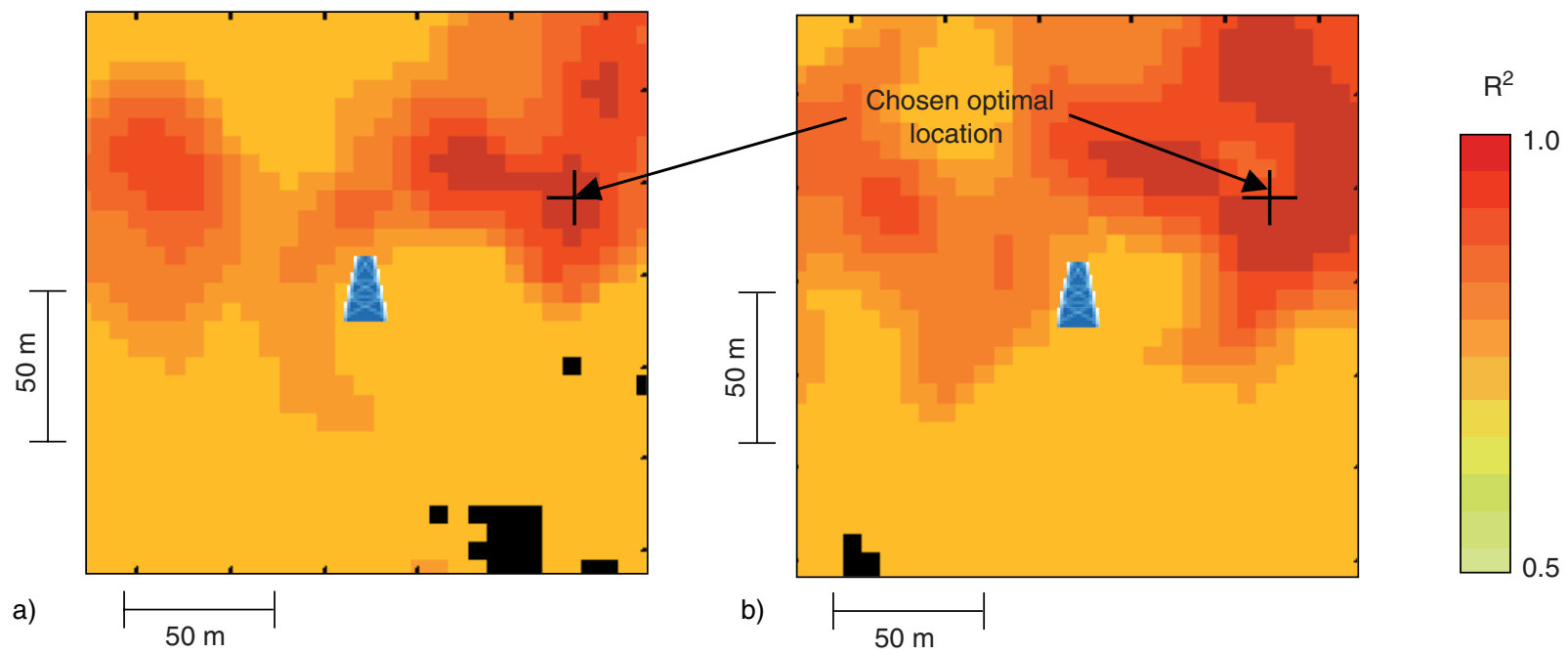

Figure 5

Example of optimal R2 maps, obtained by comparing synthetic seismic trace from well log data and observed seismic traces, in the vicinity of one well, and computed for Near (a) and Far (b) angle-stacks.

display, respectively for the near and for the far angle-stacks, the variations of RMS amplitudes in the Oligocene reservoir zone. Low values in the northern part are associated with high attenuation.

During the study, we also consider 8 regional horizons, which delineate the main channel sequences, and a low-frequency velocity model (Turpin et al., 2003), derived from the migration velocity field.

Finally, we make use of the well-log database, which is composed of 40 wells, 13 of which provide anisotropy cor- rected $I_{p}$ and $I_{s}$, as well as density (see Fig. $2 a$ and $2 b$ for a base-map view of the field with the well trajectories). Prior to the beginning of the study, these well-logs have been interpreted in terms of 8 electrofacies (Fig. 3). The first five electrofacies ( $F G 2$ to $F G 10$ ) correspond to sediments ranging from massive shales $(F G 2)$, to very unconsolidated clean sandstone deposits ( $F G 10$ or "coarse sandstones"), characterized by decreasing VClay content, as shown by Figure 3a. 3 additional electrofacies have been defined to identify heterolithic sediments (debris-flows for FG13 and FG14 and 

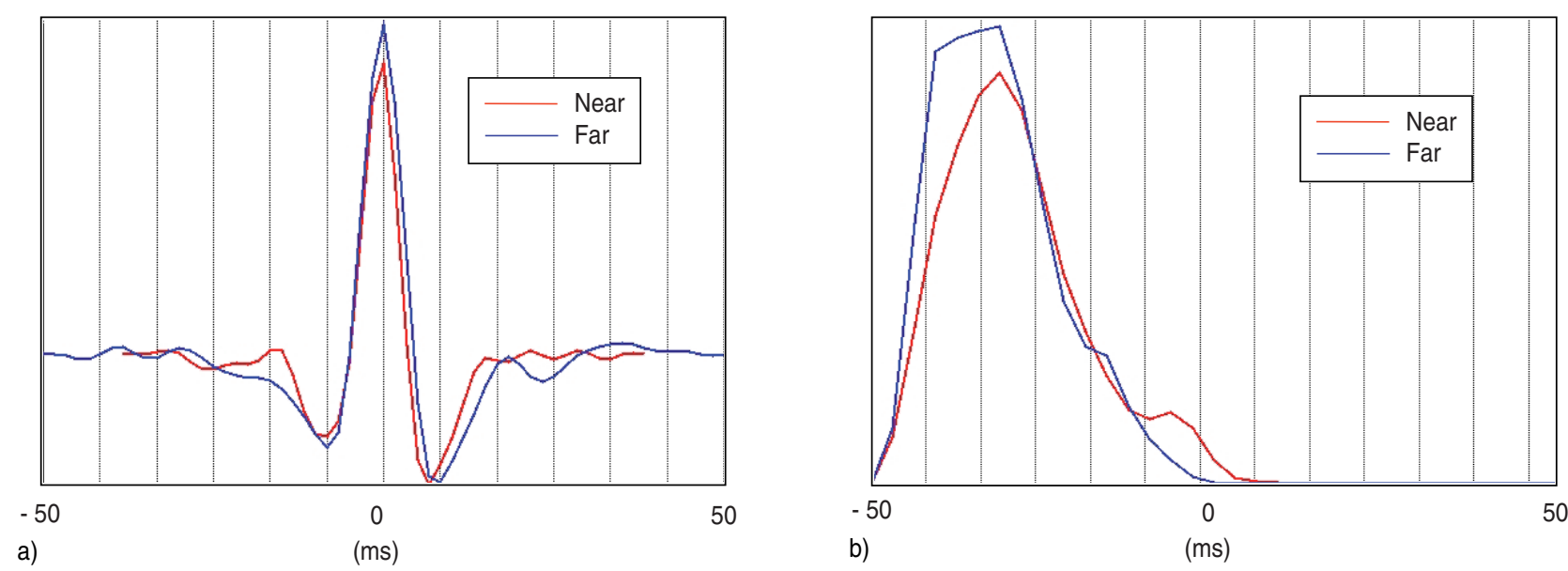

Figure 6

Optimal wavelets from well-to-seismic calibration (a) and corresponding amplitude spectra (b).

breccia lags for FG15). The Nphi-Rhob cross-plot displayed on Figure $3 \mathrm{~b}$ shows that the 8 electrofacies are also very well discriminated in terms of porosity and density. Finally, a composite view of a particular well with its electrofacies interpretation (Fig. 3c) displays a clear finingupward motif at reservoir levels, which is consistent with the gamma-ray trend, and with channel infill successions in turbidite reservoirs.

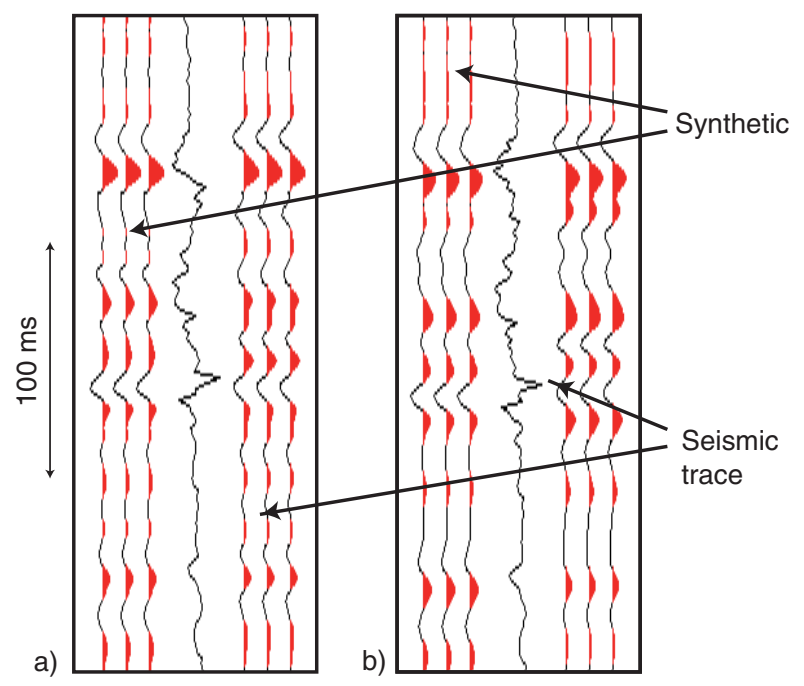

Figure 7

Comparison between seismic trace at optimal well location and synthetics computed from well $\log$ data and wavelets displayed in Figure 6; a) Near angle-stack and b) Far anglestack.

\subsection{Pre-Stack Stratigraphic Inversion}

\subsubsection{Well-to-Seismic Calibration}

After running the Multi-Coherence analysis separately on the near and on the far angle-stacks, a multi-well wavelet extraction process is initiated with a 0 -phase angle-dependent wavelet. This analysis has been performed by considering 4 wells, and by extracting a $31 \times 31(187.5 \times 187.5 \mathrm{~m})$ corridor trace around each well path. The resulting optimal linear phase wavelets are characterized by a 0 ms average time shift and a $10^{\circ}$ average phase shift both on the near and on the far angle-stacks. Figures $4 \mathrm{a}$ and $4 \mathrm{~b}$ display for one particular well a map of optimal time-shifts to be applied to well-logs for optimal match between seismic and synthetic data computed with the optimal linear phase wavelets. These maps are very similar for both angle-stacks, indicating that NMO residuals are very low. Figures $5 \mathrm{a}$ and $5 \mathrm{~b}$ are the corresponding $R^{2}$ coefficient maps between seismic and synthetic data.

Optimal well-to-seismic location is then searched in the zones with high $R^{2}$ values on both angle-stacks. Because Figures $5 \mathrm{a}$ and $5 \mathrm{~b}$ are very similar, it is very easy to find an optimal common position to both angle-stacks (black cross on the previous maps). Finally, considering these optimal locations, the linear phase wavelets are optimized using the variable phase and amplitude analysis. The resulting wavelets and their associated amplitude spectra are displayed respectively on Figures $6 \mathrm{a}$ and $6 \mathrm{~b}$. As could be expected, the frequency bandwidth is shifted to low-frequencies when angle increases, because of NMO stretch. The computed $R^{2}$ coefficients between synthetic and seismic data are very high, around 0.85 for all wells, indicating good local consistency between seismic and well log data. Figure 7 illustrates 

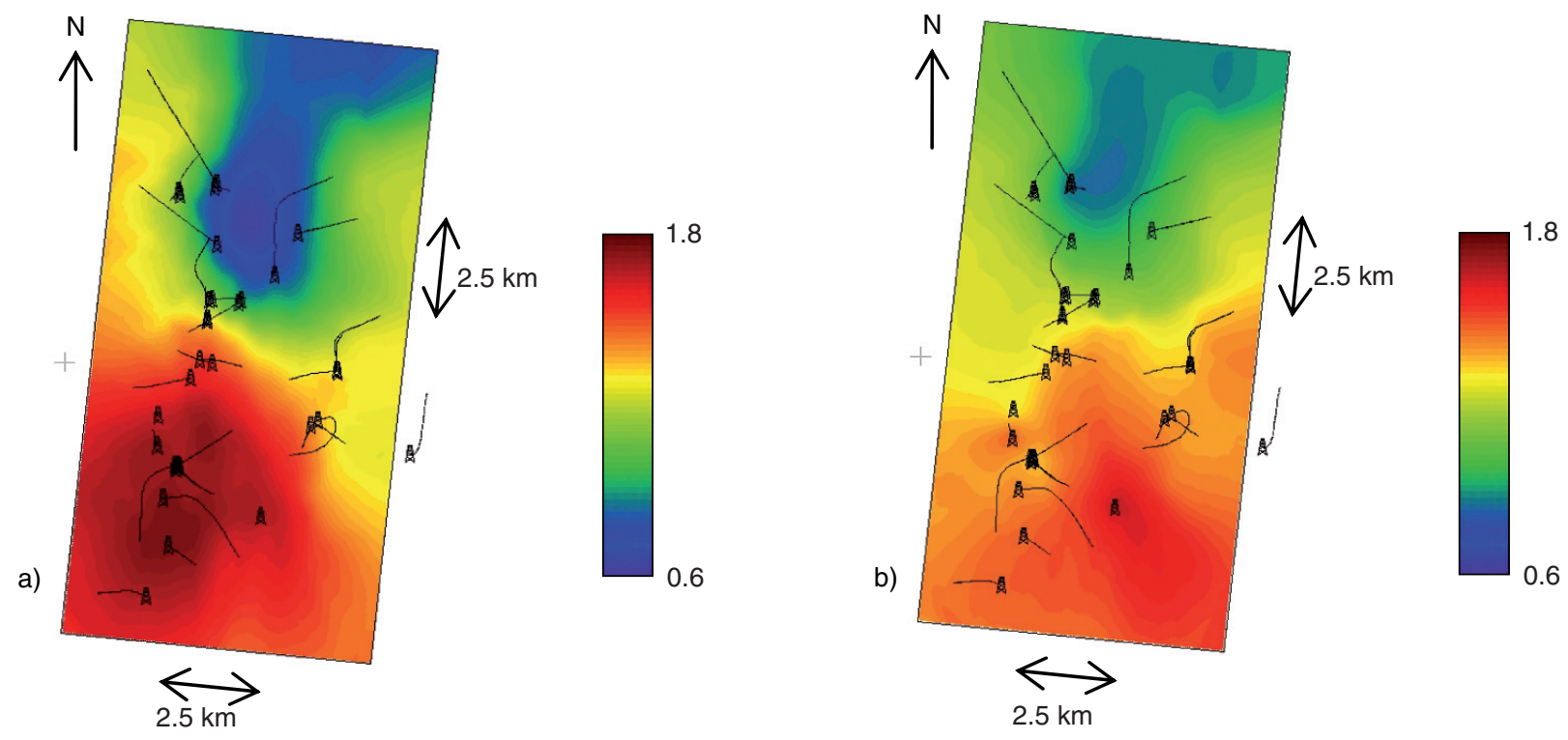

Figure 8

Wavelet multiplier maps obtained to compensate for seismic attenuation lateral variations for Near (a) and Far (b) angle-stack.

this good fit, by comparing the seismic data extracted at an optimal well position with the synthetic data computed from well $\log$ data. Additional 5 wells have then been relocated to optimal positions using the previously estimated optimal wavelets. $R^{2}$ coefficients between synthetic and seismic data remain high for these 5 wells ( $>0.7$ ), indicating a good stability of wavelet phase and origin in the Girassol field.

\subsubsection{Corrections for Lateral Variations in Wavelet Energy}

Well-to-seismic calibration shows that the energy ratio between synthetic and seismic data varies between wells. If we had not compensated for these variations, the inversion procedure would tend to under-estimate the reflection coefficients in attenuated zones. The resulting $I_{p}$ and $I_{s}$ values would therefore be erroneous. To compensate for these energy variations, we have to compute for each angle-stack a wavelet multiplier map, the role of which is to incorporate the attenuation effects on the wavelets, thereby allowing a valid estimation of reflection coefficients. Moreover, these maps should be constrained at well positions to be consistent with the local synthetic-to-seismic energy ratio computed during well-to-seismic calibration. Therefore, we have interpolated the wavelet multipliers computed at wells by kriging, taking smoothed RMS amplitude maps (Fig. $2 a$ and $2 b$ ) as external drifts. Figures $8 \mathrm{a}$ and $8 \mathrm{~b}$ display the resulting wavelet multiplier maps for respectively the near and the far angle-stack.

\subsubsection{A priori Model Construction}

The procedure interpolates well logs along correlation surfaces, which have to reflect the stratigraphic framework in each geological unit. Seismic modeling tools (Bourgeois et $a l ., 2004)$ have been used extensively at this stage to determine the most realistic stratigraphic setting for each unit. Figure 9 illustrates one of these tests, where a conceptual geological model has been considered under different stratigraphic hypotheses. After comparing the modeled seismic with observed seismic, the preferred model was finally parallel to top for the displayed channel sequence.

To better constrain the low-frequency component of this model, which cannot be updated by inversion, we have integrated a velocity model (Turpin et al., 2003) in the interpolation procedure. The quality of this velocity model, which gives information in the $0-3 \mathrm{~Hz}$ frequency range, has first been tested by comparison with low-frequency velocity well log data. Since the correlation between these data is reasonnably good $\left(R^{2}=0.75\right)$, the velocity model could be used to constrain the interpolation of well log data. Figures 10A and 10B display the smoothly varying $I_{p}$ and $I_{s}$ a priori model.

\subsubsection{Joint Pre-Stack Inversion}

Figures $11 \mathrm{~A}$ and $11 \mathrm{~B} I_{p}$ and $I_{s}$ obtained by stratigraphic inversion. Both results exhibit very good spatial resolution, which is better than that of the seismic amplitudes: a highimpedance sinuous shale plug is clearly visible both on $I_{p}$ and 


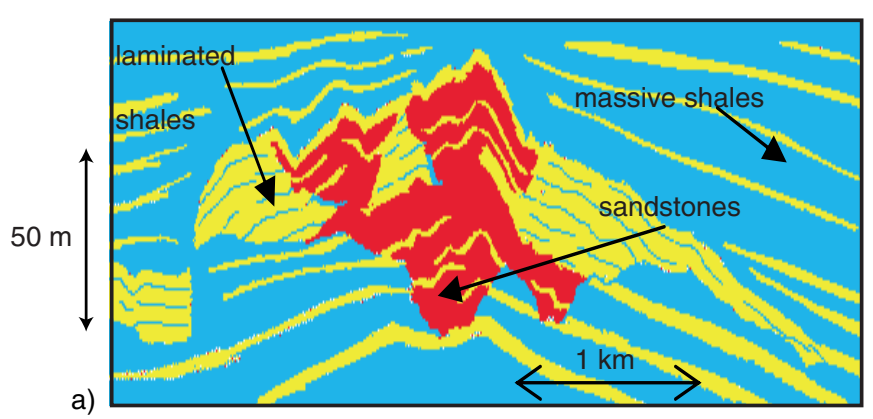

b)

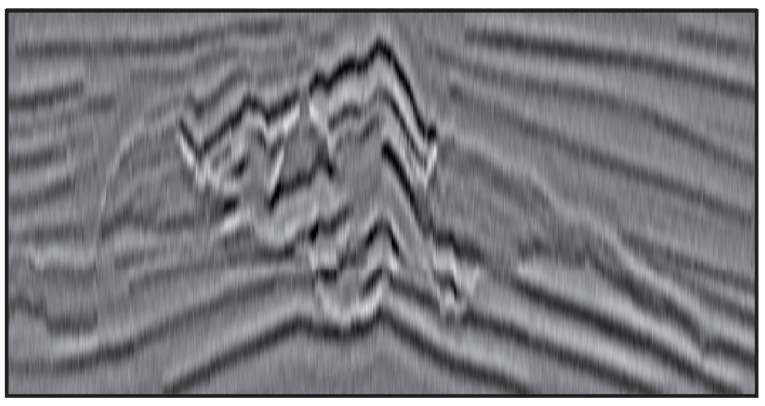

c)

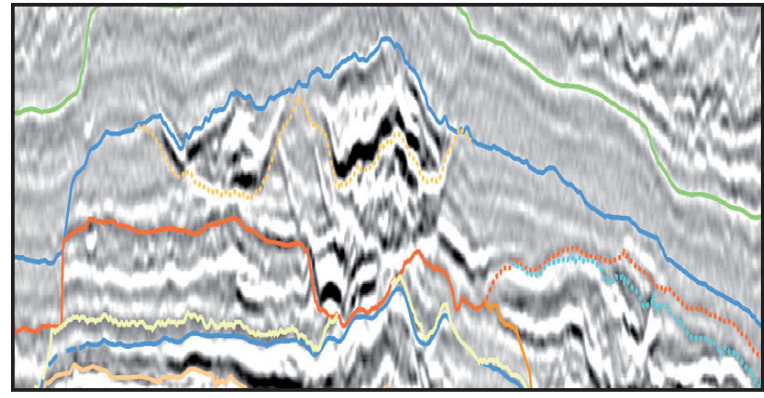

Figure 9

Conceptual geological model with a layering parallel to top in channel area (a) associated with seismic data (c), and synthetic seismic (b) computed from the geological model (a).

$I_{s}$ results. Low-impedance anomalies located inside the meanders correspond to reservoir sandstones. Note also that these anomalies tend to be less visible towards the South, which is due to the influence of structure: southern area are located on the edges of the anticline, and therefore will tend to have higher impedances. Thanks to the whitening of the spectra obtained through inversion, the vertical resolution of these results is also improved: at $-6 \mathrm{~dB}$, the $I_{p}$ reflection coefficient bandwidth reaches $130 \mathrm{~Hz}$, while the $I_{s}$ reflection coefficient bandwidth reaches $110 \mathrm{~Hz}$. These values can be compared with the $91 \mathrm{~Hz}$ and $76 \mathrm{~Hz}$ upper limits of respectively the near and far angle-stacks.

To validate the inversion results, we first examine the residual amplitude volumes, which are the difference between initial amplitudes and synthetics associated with the optimal model (Fig. 12a and 12b, where the palette dynamics is the same as on Figures $1 a$ and $1 b$ ). On both angle-stacks, residuals have low energy, and exhibit no a)
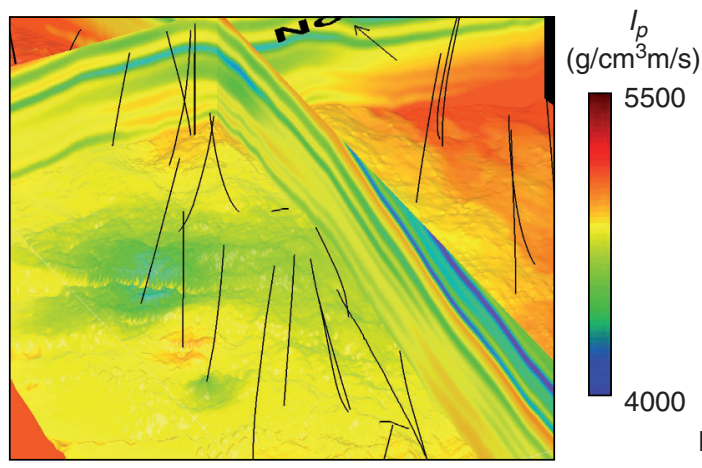

b)

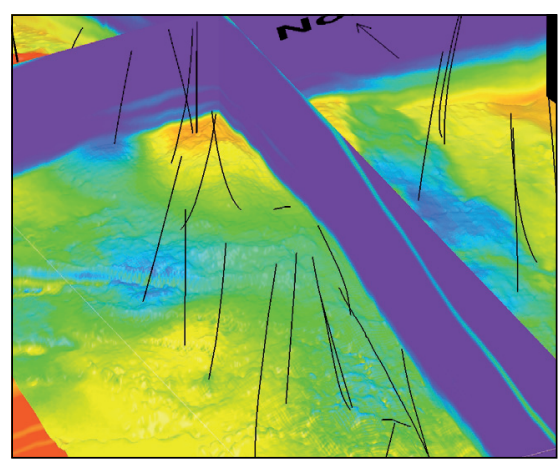

Figure 10

A priori models for Ip (a) and Is (b). 
a)
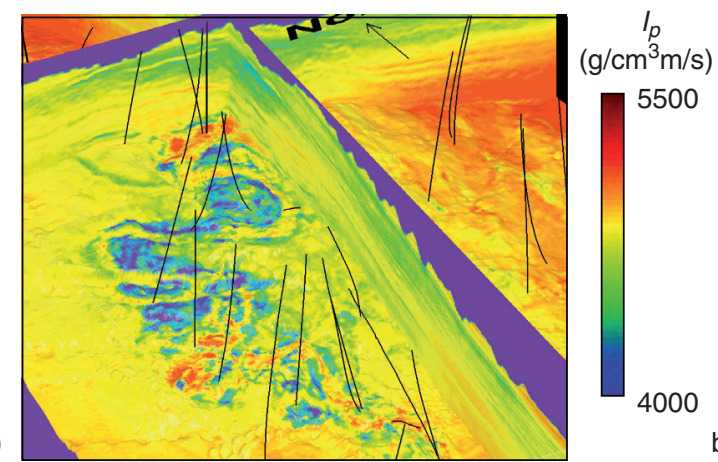

b)

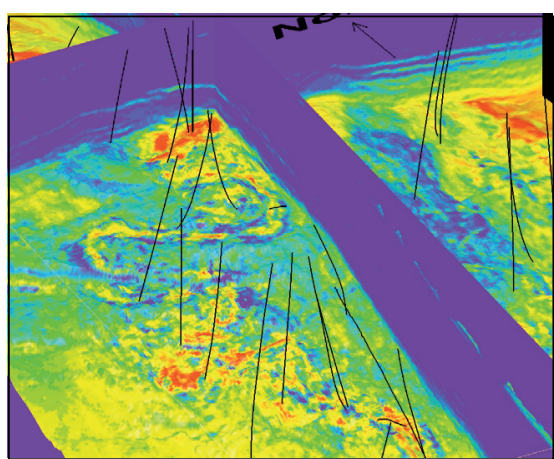

Figure 11

Optimal models for $I p$ (a) and $I s$ (b).

a)

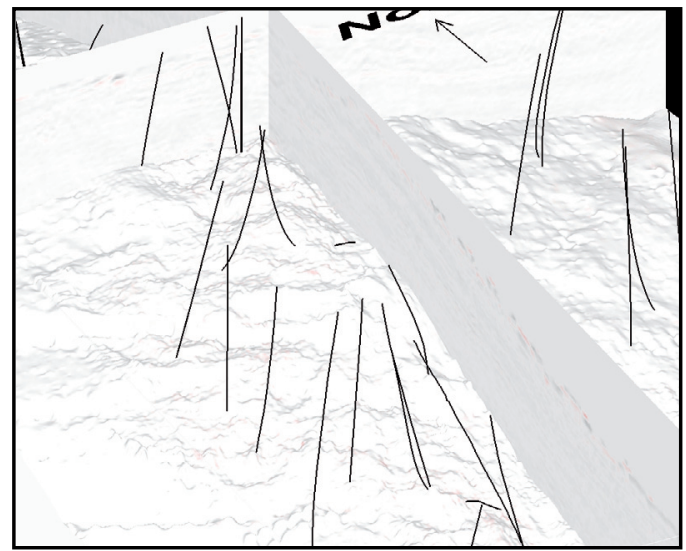

b)

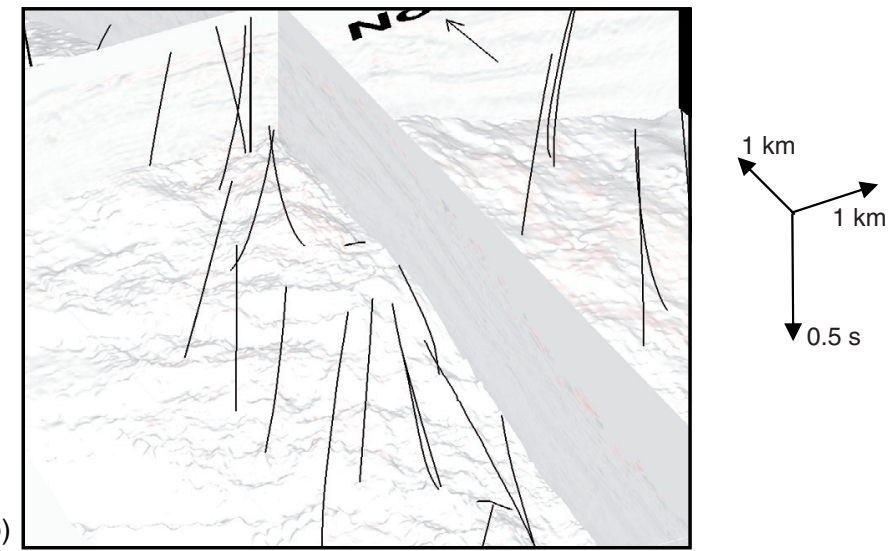

Figure 12

Residual amplitudes after stratigraphic inversion for Near (a) and Far (b) angle-stacks.

coherent spatial character; they contain mainly noise. A second quality check is made at well locations. We observe a good agreement between inversion results and well $\operatorname{logs}$ (Fig. 13a). More globally, when comparing inversion results with low-pass filtered well-logs (Fig. $13 \mathrm{~b}$ for $I p$ and $13 \mathrm{c}$ for $I s)$, we observe the inversion results are globally unbiased (no systematic departure from the red line, which corresponds to the first bissector line). Finally, dispersion in these cross-plots around this bisector line remains reasonable: the $R^{2}$ coefficient computed between these data and the first bissector line is respectively 0.75 for $I p$ and 0.70 for $I s$. The inversion results can therefore be considered as good quality (although not perfectly matching well data). They can now be interpreted in terms of seismic facies.

\subsection{Seismic Facies Analysis}

Prior to run 3D seismic facies analysis, the first issues to be addressed concern the definition of seismic facies and seismic attributes used to discriminate between the different seismic facies.

The simplest solution to integrate the geological information contained in the electrofacies interpretation of well-log data (Fig. 3c) could be to use directly well data as the training database to calibrate the classification function and then apply this calibrated relationship to predict facies elsewhere in the interwell space. However, one has to be very careful while applying this type of approach since:

- well data (logs and geological facies) and seismic data are not defined at the same scale and resolution; 


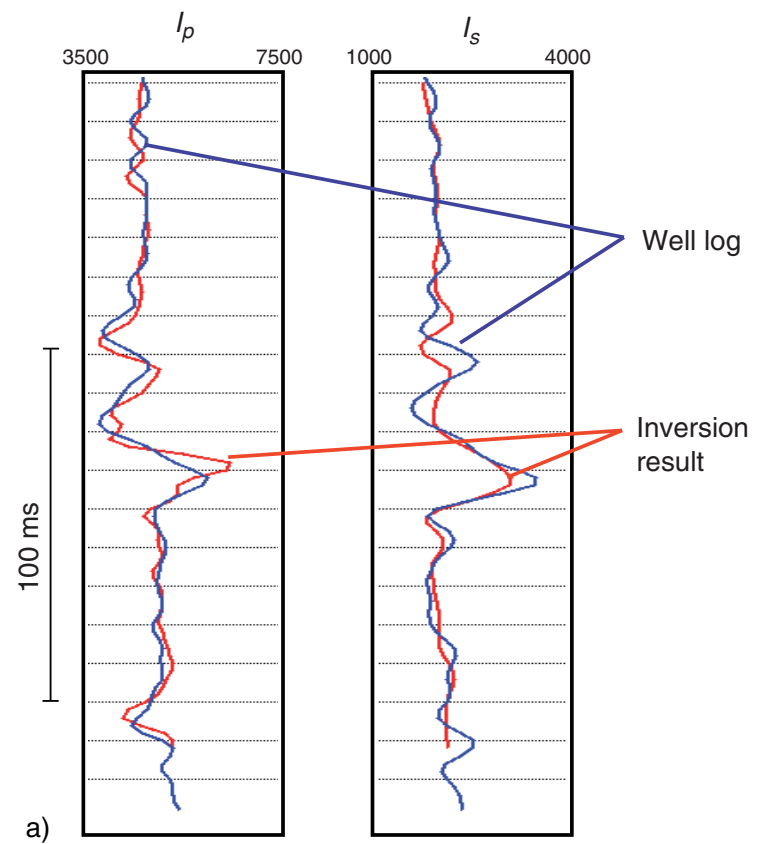

Figure 13

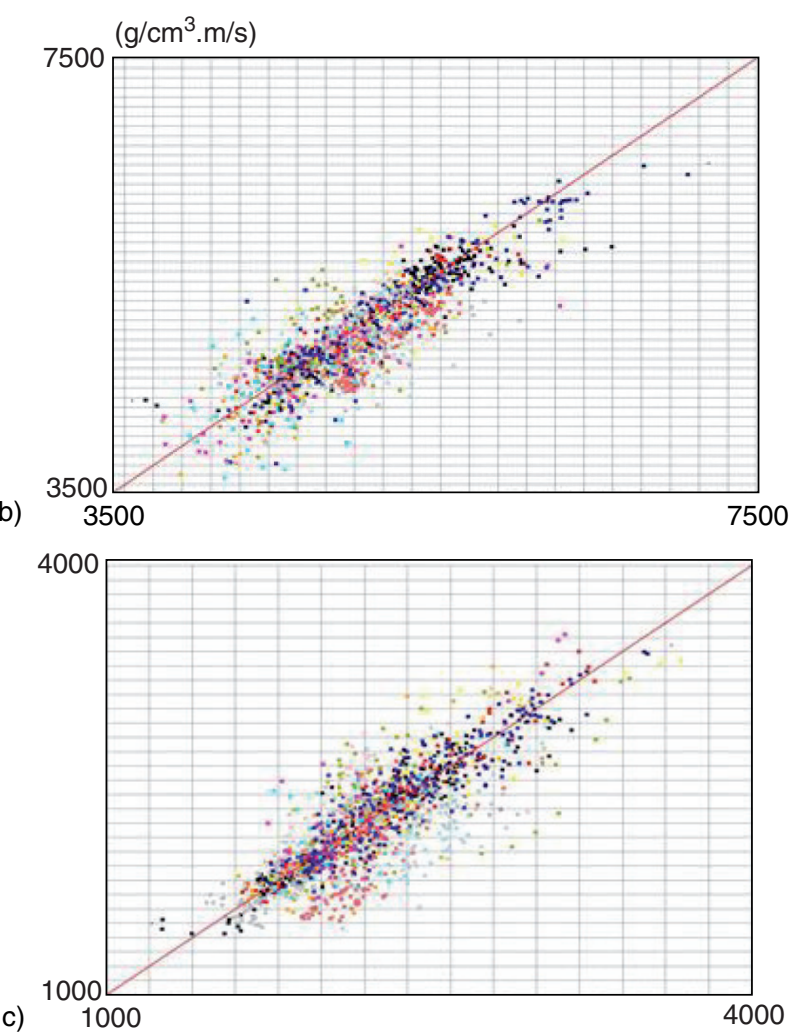

Comparison between low-pass filtered impedances from well-log data and inversion results for one well (a), and cross-plot between inversion results and low-pass filtered well-logs for $I p(\mathrm{~b})$ and $I S$ (c).

- seismic information is generally poorer than well information: typically, we will only dispose of 2 independent quantities derived from inverted $I_{p}$ and $I_{s}$ to discriminate between seismic facies, in comparison with the whole suite of well-logs available to discriminate geological facies.

To address these issues and try to keep a geological constraint in seismic facies definition, we have successively tested the discrimination between the geological facies at well-log scale and then at seismic scale.

\subsubsection{Discrimination at Well-Log Scale}

Figure 14a, which displays well data, interpreted in terms of geological facies projected in Ip-Is crossplot, clearly shows that discrimination is not possible using only $I_{p}$ and $I_{s}$ : the global rate of agreement obtained by direct reassignment test on the training database is as low as 50\%, meaning that it is only possible to correctly interpret half of the well from $I_{p}$ and $I_{s}$.

One of the causes for this low agreement rate is the compaction effect, which results in a global increase of impedances with depth. In the Girassol field, this effect is remarkable due to the anticline structure of the field and to the complex history of deposition, which results in multiple reservoir intervals. To attenuate this effect, $I_{p}$ and $I_{s}$ have been detrended by filtering out the low-frequency component
(0-0-4-8 Hz) of $I_{p}$ and $I_{s}$. Figure $14 \mathrm{~b}$ displays that the discrimination between the facies has been greatly improved. Quantitatively, the direct reassignment test score increases to $63 \%$, which is essentially due to a better identification of facies $F G 2, F G 6$ and $F G 10$. However, the three "heterolithic facies" ( $F G 13, F G 14$ and $F G 15$ ) remain poorly discriminated one from the other. Consequently, these three facies have been grouped into a single facies group. The direct reassignment test score after this operation is $68 \%$, which is acceptable for going on with the analysis. Figure $14 \mathrm{c}$ shows at a particular well that facies analysis results from detrended impedances and initial electrofacies at a particular well, are globally in good agreement.

As a summary, discrimination between geological facies from impedances is possible after removing the low-frequency trend from impedances, and after grouping heterolithic facies. In the following, we will consider these detrended attributes and 6 facies.

\subsubsection{Discrimination at Seismic Scale}

Since seismic data are defined at a coarser scale than well-log data, discrimination between the 6 facies mentionned above from detrended impedances should be also tested at seismic scale, prior to apply it to inverted data. Figure 15 compares 

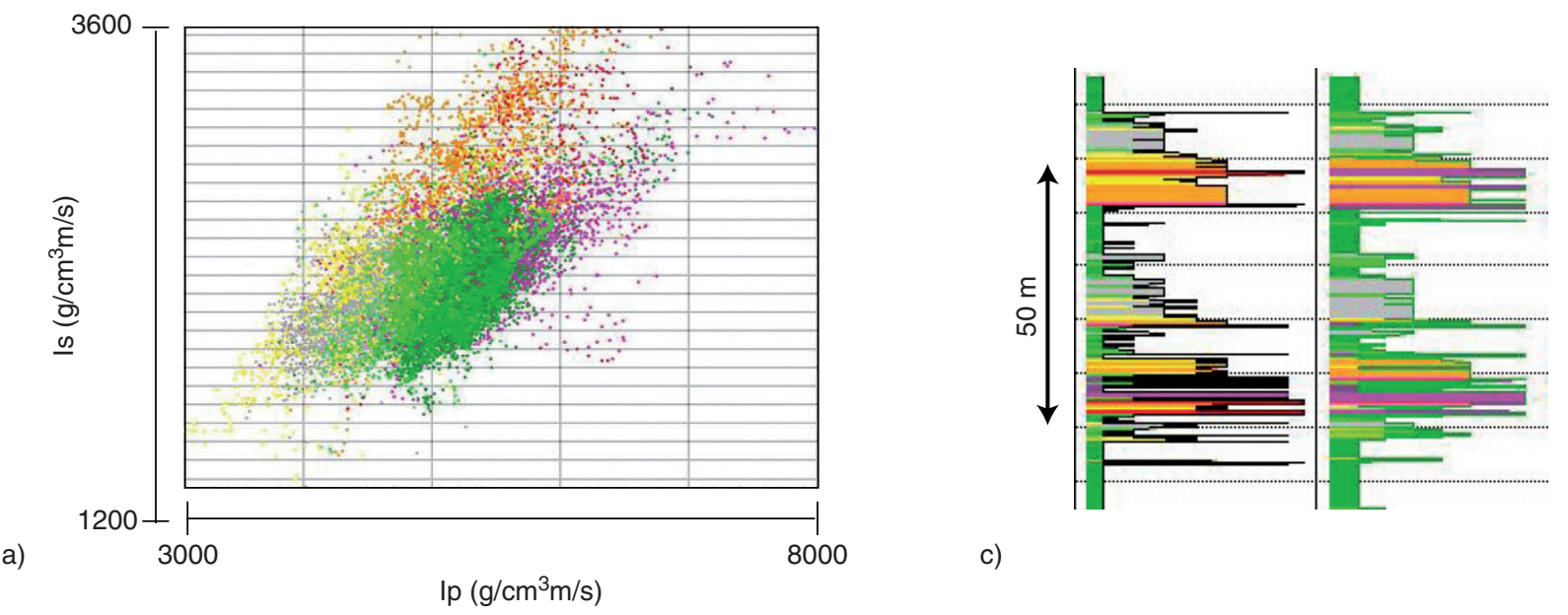

c)
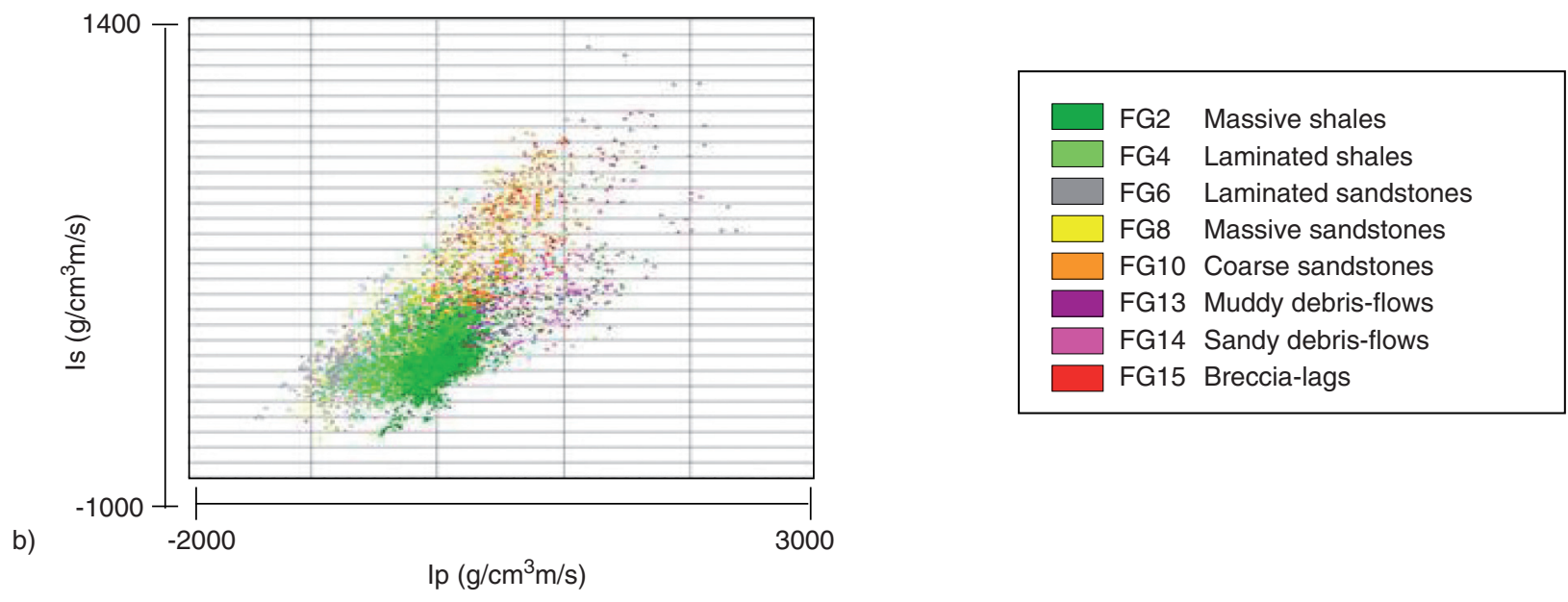

Figure 14

Discrimination of geological facies in Ip-Is crossplot before (a) and after (b) detrending well-log data and comparison between initial and predicted facies log after detrending impedances and grouping heterolithic facies (c).

initial facies $\log$ (described at well-log scale) with facies $\log$ predicted from detrended impedances (derived from well log data) at seismic scale. This figure shows a global good agreement between both analyses, meaning that the main reservoir heterogeneities can be properly identified from detrended impedances at the seismic scale. Moreover, the global vertical organization of facies (fining-upward trend) is preserved at the seismic scale.

In order to avoid confusion with electrofacies or geological facies, which have a direct and quantitative interpretation at the well-log scale, we will designate facies at the seismic scale as seismic facies SF2, SF4, SF6, SF8, SF10 and SF15.

\subsubsection{Seismic Facies Analysis}

In order to run seismic facies analysis, we could have calibrated directly seismic facies to detrended impedances derived from well-logs at the seismic scale. This approach would then have consisted to extend the interpretation displayed on Figure 15b to the whole field, based on the low-cut filtered impedance estimated by inversion. However, this approach did not lead to satisfactory results: at well position, even though misfits between well-logs and inversion results are acceptable, the are sufficient to create inconsistencies in the seismic facies model. To correct these inconsistencies, we have therefore recalibrated the discrimination between seismic facies and detrended impedances based on the following data: the training database is composed of $5 \times 5$ corridor traces extracted around well positions from detrended inverted $I_{p}$ and $I_{s}$, seismic facies being obtained from the interpretation of well-log data at the seismic scale (Fig. 15b as an example). Thanks to the large number of training data, we could use a non-parametric estimate of probability density functions (ker- 

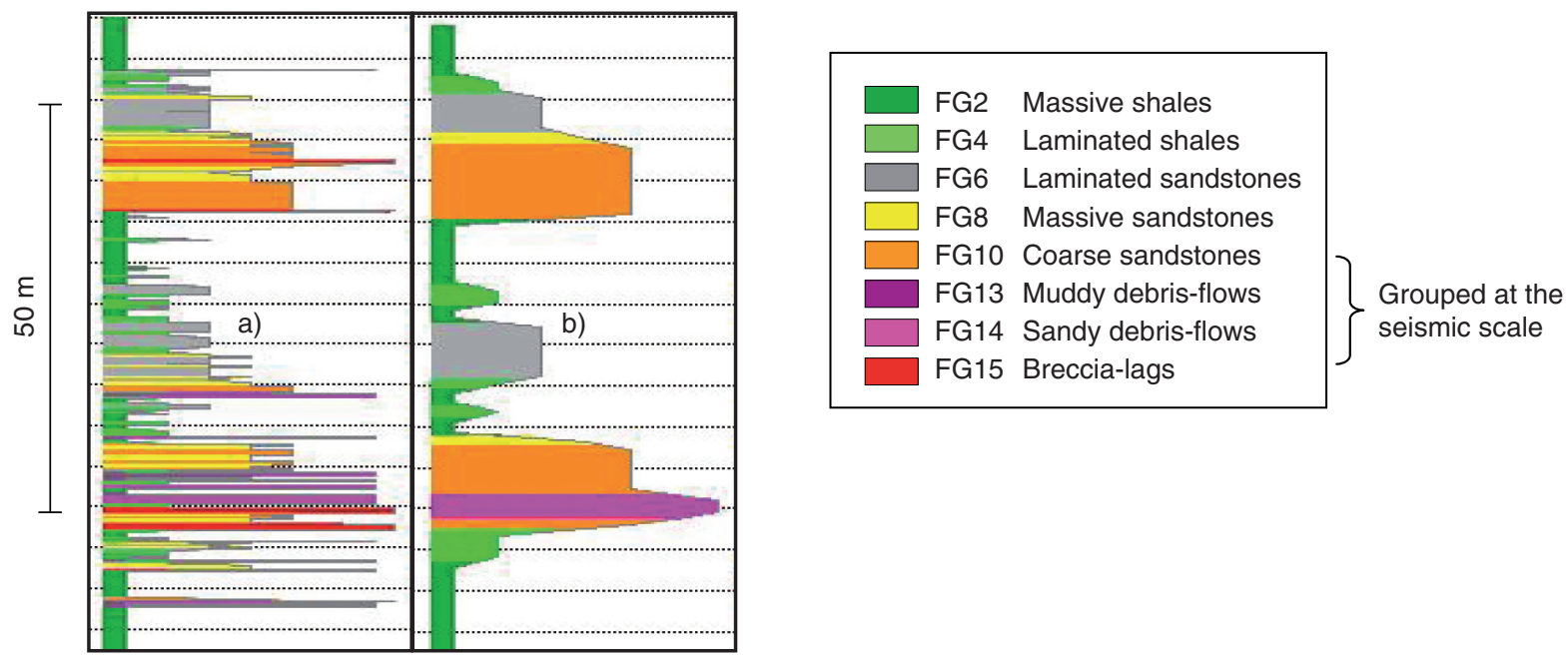

Figure 15

Comparison between initial electrofacies interpretation of well log data (a), compared with interpretation of detrended Ip and Is at the seismic scale (b).

a)

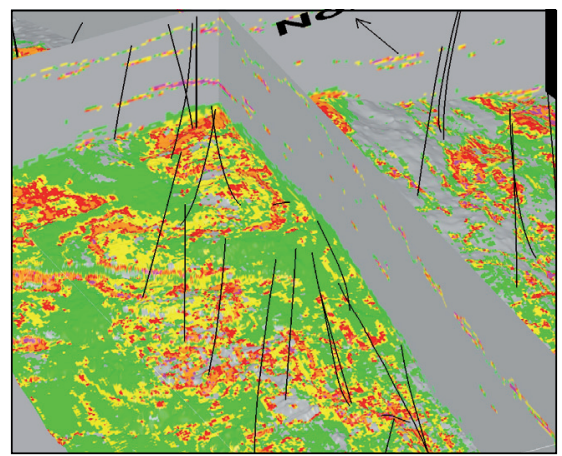

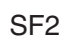

SF4

SF6

SF8

SF10

SF15

b)

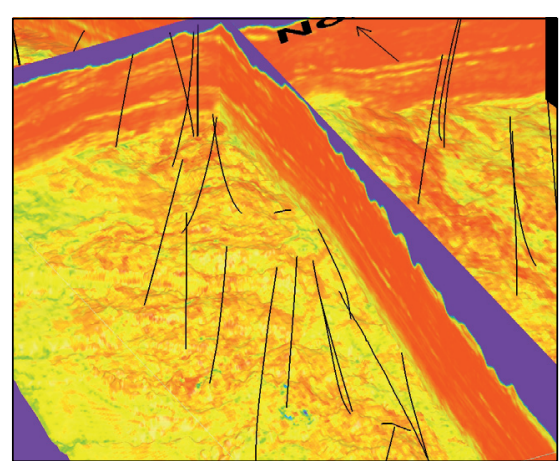

Is $(\mathrm{g} / \mathrm{cm} 3 \mathrm{~m} / \mathrm{s})$

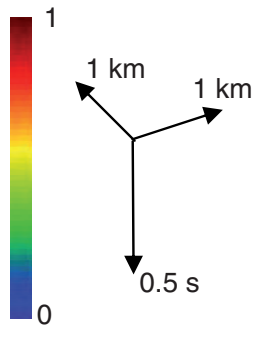

Figure 16

Most probable seismic facies (a) and associated probability (b).

nel method). The cross-validation tests performed on the training database gave excellent results with an average of $85 \%$ of training data correctly discriminated. The classification function has then been used to predict 6 seismic facies probability cubes. Figures $16 \mathrm{a}$ and $16 \mathrm{~b}$ display the most probable seismic facies cube, and its associated probability cube. It displays the spatial organization of seismic facies for a typical channel sequence; a fining-upward trend of seismic facies (from orange to grey) can be seen. Laterally, channels are surrounded by green seismic facies, which are interpreted as silty levees. Probabilities associated to this interpretation are high; they are slightly lower in the channel sequences, where geology changes rapidly. In conclusion, 3D seismic facies analysis identifies qualitatively the main geological features of Girassol field. However, this interpretation is incomplete for two main reasons: first, seismic facies are not directly linked with geological facies since seismic resolution is limited with respect to the size of geological heterogeneities; and second, probabilities cannot be interpreted as proportions of geological facies. Consequently, seismic facies analysis results need to be recalibrated to geology.

\subsection{Construction of 3D Seismic Constraint}

Use of equation 5 allows computation of the expected proportions of geological facies by combining seismic facies proportions with distributions of geological facies proportions from seismic facies estimated at well positions. However, such direct derivation may not be very useful for seismic constraint definition, since distributions of geological facies proportions display a lot of dispersion (see Fig. 17 for distributions of geological facies proportions for seismic facies $S F 8$ ). This dispersion is due to the non-uniqueness of 


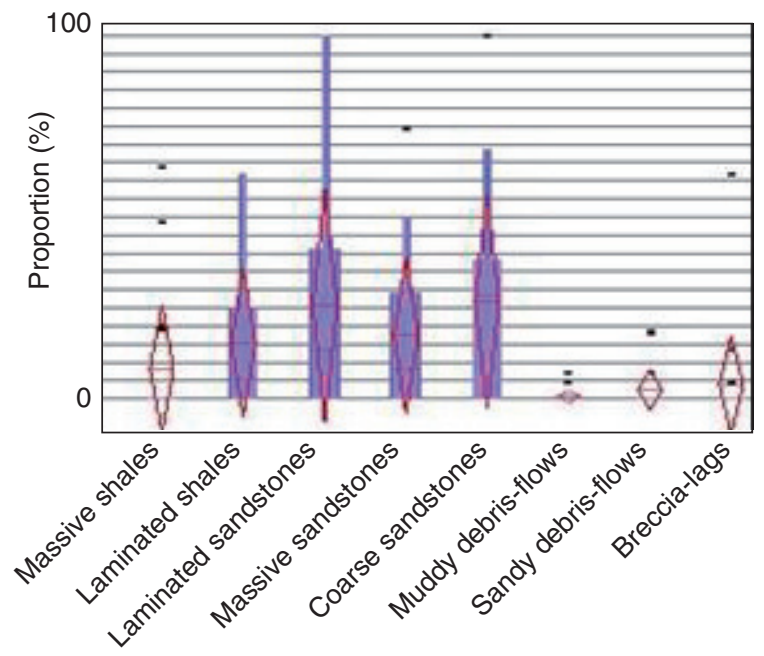

Figure 17

Distributions (box-plots) of geological facies proportions for seismic facies SF8 obtained on the whole well database.

the correspondence between geological facies proportions and seismic facies, which varies spatially.

In order to better constrain the computation of geological facies proportion by seismic facies required by Equation 5 , we have considered separately the computation of geological facies proportions in each of the 9 "geological units" already used to build the a priori model for inversion. We have therefore taken into account "stratigraphic" non-stationnarity in the computations. Figures $18 \mathrm{a}$ and $18 \mathrm{~b}$ show resulting average shale and sandstone proportion volumes. Reservoirs are very well delineated in these displays.

As an ultimate quality control of this analysis, vertical proportion curves extracted at well positions fit very well with vertical proportion curves obtained from the upscaling of electrofacies at the seismic scale (Fig. 19).

\section{CONCLUSIONS}

This paper has described a workflow to characterize Girassol reservoir properties from seismic data acquired before the start of production. This work has benefited from the excellent spatial resolution of the seismic data. We have shown that building a 3D constraint from seismic for geological modeling was not straightforward. It has first required a prestack inversion, which allows estimating an optimal elastic parameter model from seismic amplitudes, while increasing the resolution of seismic. This first phase has clearly shown the importance of properly calibrating seismic with other data such as well logs. It has also shown that because of the size of the seismic cubes, the hypothesis that the wavelet was stationary over the whole seismic cube was wrong, and that it was necessary to correct for this assumption. From the results of the inversion, we could derive seismic facies probability cubes. In order to obtain meaningful results we have first performed a detailed analysis of well data to build the facies database, then applied an appropriate impedance detrending to compensate for compaction and finally analysed the vertical upscaling process from the log to the seismic scale and executed a non-linear interpretation of seismic attribute cubes before recalibrating the resulting seismic facies to geology.

Despite the high resolution of the resulting seismic constraint, some improvements may be achieved, especially by better estimating the non-stationnarity in the last seismic constraint definition phase.

These cubes have been used in further work as a non-stationary constraint to build an initial detailed geostatistical geological model (Lerat et al., 2006), which will be used as an input in history matching, constrained with 4D seismic data (Mezghani et al., 2004).

\section{ACKNOWLEDGEMENTS}

The authors would like to thank SONANGOL, Sociedade Nacional de Combustíveis de Angola, Esso Exploration a)

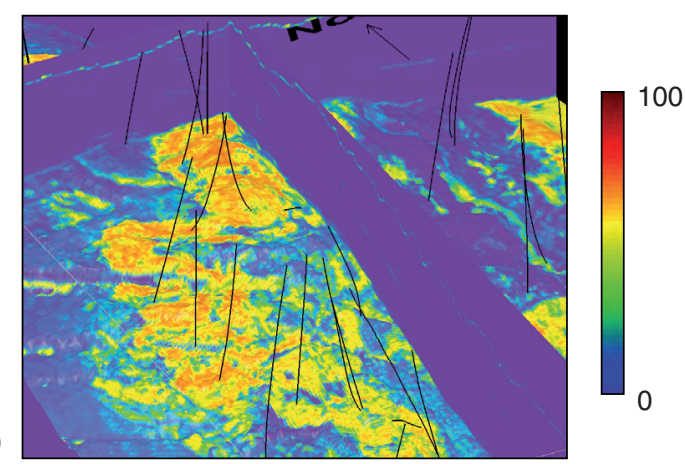

b)

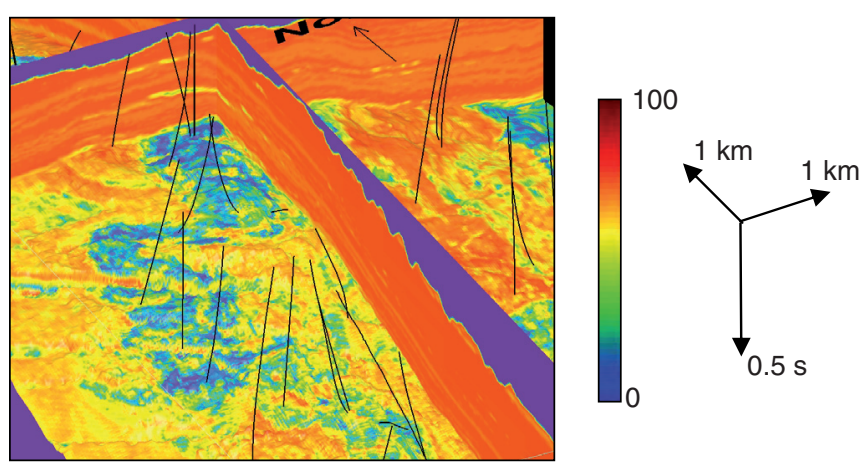

Figure 18

Average sandstone (a) and shale (b) proportions (in \%). 


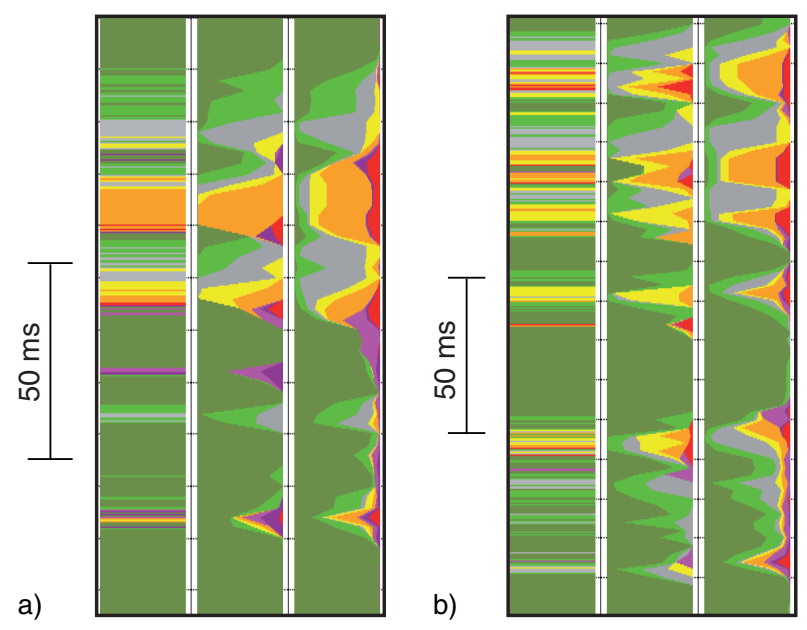

Figure 19

Comparison for two wells between electrofacies interpretation of well logs, Vertical proportion curve derived there from at the seismic scale and proportions computed from seismic data.

Angola (Block 17), BP Exploration (Angola), Statoil Angola Block 17 A.S., Norsk Hydro, Total Angola and Total for permission to present this paper. Olivier Lerat, Thierry Tonellot, Nathalie Lucet and Frédéric Roggero are also acknowledged for the fruitful discussions and contributions to some aspects of this paper.

\section{REFERENCES}

Aki, K. and Richards, P.G. (2002) Quantitative seismology: Theory and methods, 2nd edition. University Science Books, Sausalito.

Barens, L. and Biver, P. (2004) Reservoir facies prediction from geostatistical inverted data. SPE - 11th International Petroleum Conference and Exhibition, paper 88690.

Bourgeois, A. Joseph, P. and Lecomte, J.-C. (2004) Three-dimensional full wave seismic modelling versus one-dimensional convolution: the seismic appearance of the Grès d'Annot turbidite system. Geol. Soc. London, 221, S401-S417.

Dash, B.L. and Obaidullah, K.A. (1970) Determination of signal and noise statistics using correlation theory. Geophysics, 35, 24-32.

Doligez, B., Gomel, P., Andrieux, B., Fournier, F. and Beucher, H. (2003) Use of seismic to constrain geostatistical reservoir models: a quantitative approach using proportions of facies. AAPG - Annual Convention, Salt Lake City, 11-14 May, paper 78165.

Fournier, F., and Derain, J.-F. (1995) A statistical methodology for deriving reservoir properties from seismic data. Geophysics, 60, 1437-1450.
Hand, D.J. (1981) Discrimination and classification. Wiley Series in Probabilities and Mathematical Statistics, John Wiley \& Sons, Chichester.

Hohn, M.E. , McDowell, R.R., Matchen, D.L., and Vargo, A.G. (1997) Heterogeneity of Fluvial-Deltaic Reservoirs in the Appalachian Basin: A Case Study from a Lower Mississippian Oil Field in Central West Virginia. AAPG Bull., 81, 918-936.

Lefeuvre, F., Kerdraon, Y., Peliganga, J., Medina, S., Charrier, P., L'Houtellier, R. and Dubucq, D. (2003) Improved reservoir understanding through rapid and effective 4D: Girassol field, Angola, West Africa. SEG - 73rd Annual International Meeting, Dallas, 2631 October. Expanded Abstracts, 1338-1341.

Lerat, O., Doligez, B., Albouy, E., Nivlet, P., Roggero, F., Cap, J., Vittori, J. and Duplantier, O. (2006) Integrated reservoir model: geostatistical geological modeling using a 3D seismic constraint. GCSSEPM - 26th Annual Bob F. Perkins Research Conference, Reservoir Characterization: Integrating technology and business practices, 3-6 December, Houston, Texas.

Lucet, N., Déquirez, P.-Y. and Cailly, F. (2000) Well-to-seismic calibration: A multiwell analysis to extract one single wavelet. SEG - 70th Annual International Meeting, Calgary, 6-11 August. Expanded abstracts, 1615-1618.

Mezghani, M., Fornel, A., Langlais, V., and Lucet, N. (2004) History matching and quantitative use of $4 \mathrm{D}$ seismic data for an improved reservoir characterization. SPE Annual Technical Conference and Exhibition, Houston, 26-29 September. SPE 90420.

Navarre, J.-C., Claude D., Liberelle, E., Safa, P., Vallon, G., and Keskes, N. (2002) Deepwater turbidite system analysis, West Africa: Sedimentary model and implications for reservoir model construction. The Leading Edge, 21, 1132-1139.

Nivlet, P. (2004) Low-frequency constraint in a priori model building for stratigraphic inversion. SEG- 74th Annual International Meeting, Denver, 10-15 October. Expanded abstracts, 1802-1805.

Nivlet, P., Doligez, B., Dos Santos, M.-S., Dillon L., and Schwedersky-Neto, G. (2004) Seismic facies interpretation in a turbiditic environment from pre-stack data: a case study. 66th EAGE Conference \& Exhibition, Paris, 6-10 June. D04, Extended Abstracts.

Silverman, B.W. (1986) Density estimation for statistical and data analysis. Chapman and Hall, London.

Tarantola, A. (1987) Inverse problem theory. Elsevier, New-York.

Tonellot, T., Macé, D. and Richard, V. (2001) Joint stratigraphic inversion of angle-limited stacks. SEG - 71st Annual International Meeting, San Antonio, 9-14 September. Expanded abstracts, 227230.

Turpin P., Gonzalez-Carballo A., Bertini F., and Lefeuvre, F. (2003) Velocity volume and time/depth conversion approach during Girassol field development. SEG - 73rd Annual International Meeting, Dallas, 26-31 October. Expanded abstracts, 2179-2182.

Final manuscript received in July 2006 or distributed for profit or commercial advantage and that copies bear this notice and the full citation on the first page. Copyrights for components of this work owned by others than IFP must be honored. Abstracting with credit is permitted. To copy otherwise, to republish, to post on servers, or to redistribute to lists, requires prior specific permission and/or a fee: Request permission from Documentation, Institut français du pétrole, fax. +33147527078 , or revueogst@ifp.fr. 